\title{
Image measurements of os odontoideum in children
}

\author{
Haicheng Dou, Chenglong Xie, Xiangyang Wang, Qishan Huang
}

Department of Orthopaedics, The Second Affiliated Hospital and Yuying Children's Hospital of Wenzhou Medical University, Zhejiang Spine Surgery Center, Zhejiang Provincial Key Laboratory of Orthopaedics, Wenzhou, China

Contributions: (I) Conception and design: Q Huang; (II) Administrative support: X Wang; (III) Provision of study materials or patients: H Dou; (IV) Collection and assembly of data: C Xie; (V) Data analysis and interpretation: C Xie; (VI) Manuscript writing: All authors; (VII) Final approval of manuscript: All authors.

Correspondence to: Qishan Huang. Department of Orthopaedics, The Second Affiliated Hospital and Yuying Children's Hospital of Wenzhou Medical University, Zhejiang Spine Surgery Center, Zhejiang Provincial Key Laboratory of Orthopaedics, 666, Oushi Road, Dongtou District, Wenzhou 325027, China. Email: hqshaq@126.com.

Background: Conservative therapy is used for children with odontoid fracture; however, when the odontoid fracture is complicated by significant displacement and unstable, surgery is required. Anterior cervical hollow lag screw fixation has been successfully used in adult patients, but until now, there has not been any relevant image measurement research in children with os odontoideum. The aim of the present study was to identify the morphometric changes of normal os odontoideum in children of different ages and to discuss parameters for screw fixation.

Methods: Computed tomography (CT) scanning data of normal os odontoideum in 120 children of different ages were measured. The parameters were as follows: transverse and vertical diameters of cancellous bone and cortical bone in os odontoideum basilar part, angle and distance from simulation screw insertion point (anterior mid-point of C2 vertebral body) to os odontoideum anterior angle as well as posterior angle, the optimal insertion angle, and the optimal screw length.

Results: The basilar part of normal os odontoideum was roughly round, and vertical diameter was slightly larger than transverse diameter. All parameters measured in the present study increased with age. The safety screw insertion angle range was $16-36^{\circ}$, and the optimal insertion angle ranged from $19^{\circ}$ to $22^{\circ}$. The safety screw path length ranges in the 3-5-, 6-9-, and 10-14-year groups were 8-14, 10-16, and 12-21 mm, respectively, and the optimal screw length ranges were 13-14, 15-16, and 19-20 mm, respectively. The height of the axis showed a growing dimension followed by the advancing age in all groups. In each group, the height of the axis of the male is greater than the female.

Conclusions: For children undergoing odontoid screw fixation for the treatment of type II odontoid fracture, it is important to select the appropriate screw diameter, length, and direction according to parameter changes of os odontoideum based on their age.

Keywords: Os odontoideum; odontoid fracture; anterior odontoid screw fixation; children

Submitted Nov 13, 2020. Accepted for publication Feb 03, 2021.

doi: $10.21037 /$ tp-20-416

View this article at: http://dx.doi.org/10.21037/tp-20-416

\section{Introduction}

Approximately $40-60 \%$ of spine injuries in children occur in the cervical spine, with odontoid fractures being the most common $(1,2)$. In children under 7 years of age, $75 \%$ of cervical spine injuries occur in the odontoid (3), which is mainly caused by traffic accidents $(4,5)$. Anterior cervical hollow lag screw fixation has been successfully used in adult patients, as well as in children worldwide (6-8). However, there are anatomical differences in children with normal odontoid based on age and sex. In the present study, we used 2D computed tomography (CT) reconstruction 


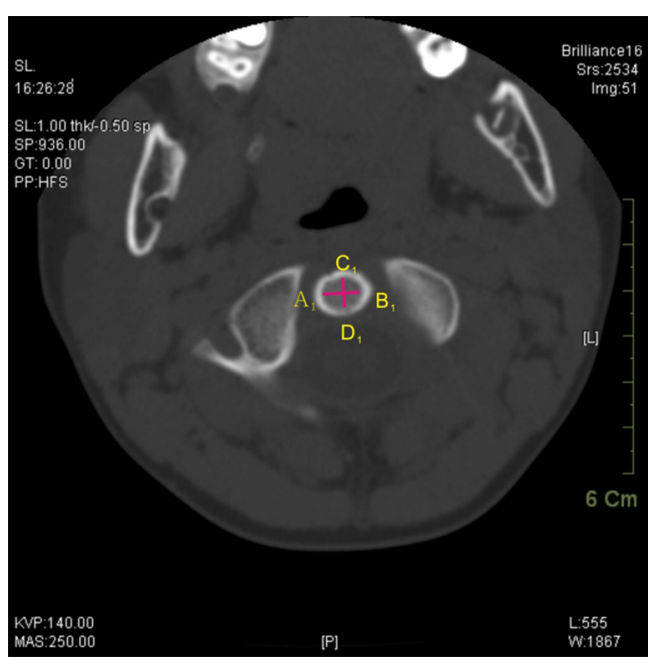

Figure 1 Measurement of odontoid cancellous bone diameter (A1BI) and odontoid cancellous bone longitudinal diameter (C1D1).

technology to identify the morphometric differences of normal os odontoideum in children of different ages, and discuss the parameters for screw fixation.

We present the following article in accordance with the MDAR reporting checklist (available at http://dx.doi. org/10.21037/tp-20-416).

\section{Methods}

\section{Materials}

CT scans of Chinese children who were treated at the Second Affiliated Hospital and Yuying Children's Hospital of Wenzhou Medical University between January 2014 and December 2019 were analyzed. Children aged 3-14 years were chosen through a stratified random sampling method from The Second Affiliated Hospital and Yuying Children's Hospital of Wenzhou Medical University. A total of 120 children ( 60 boys and 60 girls) with no spinal abnormalities (congenital deformity, trauma, and primary or secondary tumor) were excluded. According to the stage of development, the following groups were created: group 1: 3-5 years old, group 2: 6-9 years old, and group 3: $10-14$ years old. Each group had 20 boys and 20 girls.

All procedures performed in this study involving human participants were in accordance with the Declaration of Helsinki (as revised in 2013). The study was approved by Ethics Committee of the Second Affiliated Hospital of Wenzhou Medical University (No.: 2021-K-09-01).

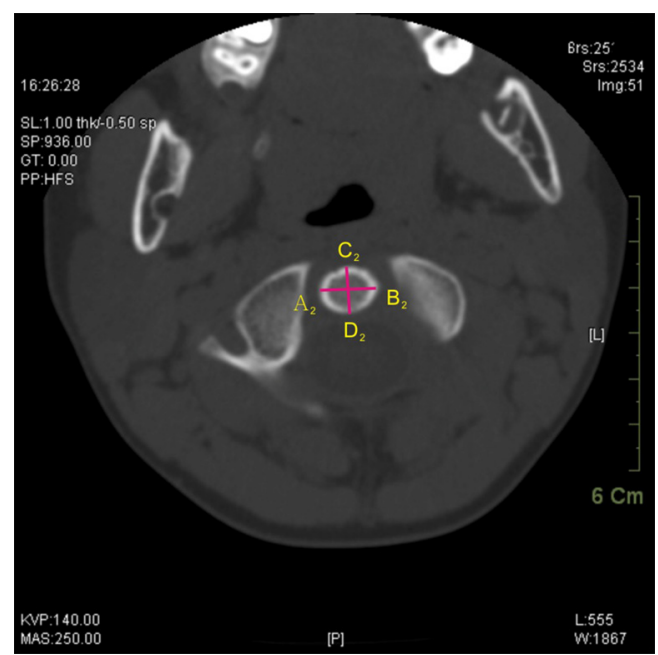

Figure 2 Measurement of odontoid cortical bone diameter (A2B2) and odontoid cortical bone longitudinal diameter (C2D2).

Individual consent for this retrospective analysis was waived.

\section{Measurement methods}

Axial CT images of each child were taken using a General Electric CT scanner (Philips Secura 16-slice; Philips Medical Systems, Eindhoven, the Netherlands). Scan parameters were as follows: $120 \mathrm{kV}, 180 \mathrm{~mA}, 512 \times 512$ matrix, slice thickness: $2 \mathrm{~mm}$, and pitch: 1.0. Multiplanar reconstructions were used to attain odontoid images of the cross-section and the median sagittal plane and to measure the parameters with using the picture archiving and communication system of The Second Affiliated Hospital and Yuying Children's Hospital of Wenzhou Medical University as follows: (I) odontoid cancellous bone diameter (A1B1): the narrowest coronal vertical distance at the base of the odontoid cancellous bone (Figure 1); (II) odontoid cancellous bone longitudinal diameter (C1D1): the narrowest sagittal vertical distance at the base of the odontoid cancellous bone (Figure 1); (III) odontoid cortical bone diameter (A2B2): the narrowest coronal vertical distance at the base of the odontoid cortical bone (Figure 2); (IV) odontoid cortical bone longitudinal diameter(C2D2): the narrowest sagittal vertical distance at the base of the odontoid cancellous bone (Figure 2); (V) simulation nail point to odontoid anterior horn length angles, posterior horn length angles, and optimal length: the median sagittal plane odontoid diagonal length), which was considered the best angle (the cobb of BOE, the included angle of 


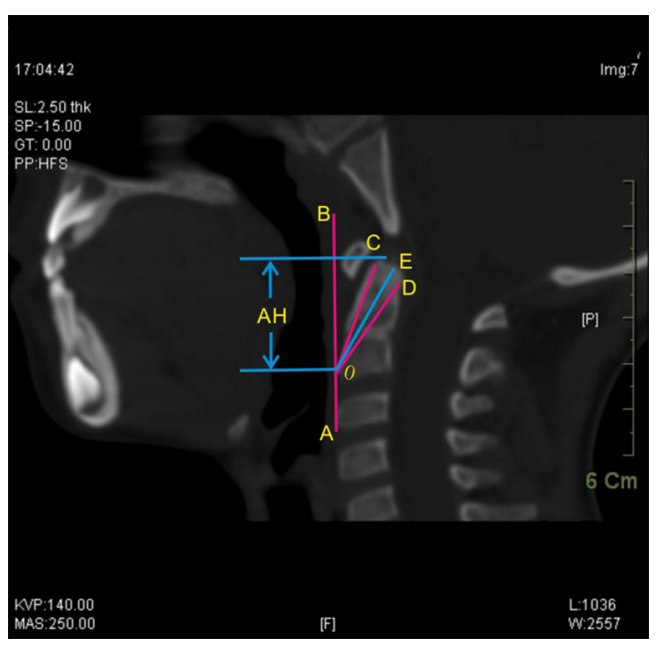

Figure 3 Measurement of simulation nail point to odontoid anterior horn length angle, posterior horn length angle, optimal length (OE), and axial height $(\mathrm{AH})$ and the cobb of BOC, the included angle of hanging line by simulating nail point with the odontoid anterior horn and the cobb of BOD, the included angle of hanging line by simulating nail point with the odontoid posterior horn and the cobb of BOE, the included angle of hanging line by simulating nail point with the odontoid angle bisector optimal length of the simulation nail point to odontoid anterior horn and posterior horn.

hanging line by simulating nail point with the odontoid angle bisector optimal length of the simulation nail point to odontoid anterior horn and posterior horn. at the median sagittal plane) (Figure 3); and (VI) axial height: the vertical distance of the odontoid tip to the odontoid anteroinferior edge (Figure 3).

\section{Statistical methods}

SPSS 17.0 software (IBM, Armonk, NY, USA) was used for statistical analysis of the data. Statistical analysis was performed using independent samples $t$-test. $\mathrm{P}<0.05$ represented statistical significance.

\section{Results}

The basilar part of the odontoid was roughly circular, and vertical diameter was slightly larger than the transverse diameter. Diameters showed that, in each group, the height of the axis of the male is greater than the female.

General results of research object: there were no significant differences between male and female patients in the 3-5-year group $(\mathrm{P}>0.05)$, but there were significant differences in the 6-9-year and 10-14-year groups $(\mathrm{P}<0.05)$ (Table 1).

Analysis of restrictive factors of screw diameter and screw angle: Simulation nails points to odontoid tip anterior and posterior horn angle showed no significant differences between male and female patients at each level $(\mathrm{P}>0.05)$; safety angle range was $16-36^{\circ}$ and the optimal angle range was $19-22^{\circ}$ (Table 2).

For the simulation nails points to odontoid tip anterior and posterior horn distance. There were no significant differences between male and female patients at each level $(\mathrm{P}>0.05)$, but there were significant differences in age groups $(\mathrm{P}<0.05)$. The safety screw path length ranges were as follows: 3-5-year group, 8-14 mm (optimal length was 13-14 mm); 6-9-year group, 10-16 mm (optimal length was 15-16 mm); and 10-14-year group, 12-21 mm (optimal length was $19-20 \mathrm{~mm}$ ). There were significant differences between male and female patients at each level $(\mathrm{P}<0.05)$, and in age groups $(\mathrm{P}<0.05)$ (Table 3).

\section{Discussion}

Bailey and Jagannathan et al. found that there are five original axial ossification centers as follows: 1 in the vertebral body, 2 in the odontoid, and 2 in the arch $(9,10)$. Vertebral ossification centers generally appear in the fifth month of gestation, the arch in the seventh month of gestation, and integration in the first 2-3 years of life. Odontoid ossification centers appear in the fifth month of gestation, and the odontoid (which at this stage is separated into 2 parts), combines in the seventh month of gestation. The odontoid apex secondary ossification center appears at s 3-6 years of age, and odontoid integration occurs at 12 years of age.

The hollow lag screw diameter depends on the minimum distance of the os odontoideum cross-section. According to our research, the odontoid cross-sectional transverse diameter is less than the longitudinal diameter, so the diameter of the screw depends on the os odontoideum transverse diameter. Nucci et al. demonstrated that odontoid inner diameter could reach $9 \mathrm{~mm}$ after expanding by surgical instruments, it can be screwed into two 3.5$\mathrm{mm}$ screws, which are better able to achieve the fixed effect against the rotation (11). Our measurement results showed that the cancellous bone average transverse diameters in the 3 groups were as follows: $3.53,4.21,4.86 \mathrm{~mm}$ for boys, 
Table 1 Cancellous cortical bone diameter and longitudinal diameter value $\left(\mathrm{mm}, \bar{x}_{ \pm \mathrm{s}}\right)$

\begin{tabular}{|c|c|c|c|c|c|c|c|c|c|c|c|c|}
\hline Parameters & \multicolumn{4}{|c|}{ 3-5-year age group } & \multicolumn{4}{|c|}{$6-9$-year age group } & \multicolumn{4}{|c|}{ 10-14-year age group } \\
\hline A1B1 & $3.53 \pm 0.89$ & $3.41 \pm 0.56$ & 0.905 & 0.371 & $4.21 \pm 0.54$ & $3.89 \pm 0.56$ & 2.519 & 0.029 & $4.86 \pm 0.68$ & $4.46 \pm 0.90$ & 1.582 & 0.022 \\
\hline C1D1 & $4.44 \pm 0.73$ & $4.33 \pm 0.65$ & 3.016 & 0.055 & $4.99 \pm 0.76$ & $4.38 \pm 0.69$ & 2.231 & 0.318 & $5.33 \pm 0.62$ & $4.96 \pm 0.47$ & 5.665 & 0.000 \\
\hline A2B2 & $5.34 \pm 0.62$ & $5.25 \pm 0.57$ & 0.894 & 0.377 & $5.50 \pm 0.80$ & $5.31 \pm 0.69$ & 2.162 & 0.043 & $5.94 \pm 0.68$ & $5.62 \pm 1.03$ & 2.037 & 0.049 \\
\hline
\end{tabular}

A1B1, odontoid cancellous bone diameter; A2B2, odontoid cortical bone diameter; C1D1, odontoid cancellous bone longitudinal diameter; C2D2, odontoid cortical bone longitudinal diameter;

Table 2 Simulation nail points to odontoid tip angle $\left({ }^{\circ}, \bar{x}_{ \pm}\right)$

\begin{tabular}{|c|c|c|c|c|c|c|c|c|c|c|c|c|}
\hline Parameters & \multicolumn{4}{|c|}{ 3-5-year age group } & \multicolumn{4}{|c|}{ 6-9-year age group } & \multicolumn{4}{|c|}{ 10-14-year age group } \\
\hline $\mathrm{BOC}$ & $17.16 \pm 1.18$ & $16.77 \pm 1.08$ & -0.152 & 0.371 & $16.99 \pm 1.54$ & $16.73 \pm 1.54$ & 1.834 & 0.074 & $16.77 \pm 1.07$ & $16.60 \pm 1.38$ & 0.098 & 0.922 \\
\hline BOD & $36.30 \pm 0.89$ & $35.74 \pm 3.87$ & 0.340 & 0.055 & $36.63 \pm 3.69$ & $35.97 \pm 4.29$ & 2.834 & 0.057 & $36.81 \pm 3.47$ & $35.89 \pm 1.80$ & -0.753 & 0.456 \\
\hline BOE & $22.72 \pm 3.35$ & $19.36 \pm 3.24$ & 1.078 & 0.054 & $22.80 \pm 4.57$ & $19.46 \pm 2.62$ & 1.971 & 0.056 & $22.98 \pm 2.21$ & $19.58 \pm 1.40$ & 0.421 & 0.676 \\
\hline
\end{tabular}

The cobb of BOC, the included angle of hanging line by simulating nail point with the odontoid anterior horn; The cobb of BOD, the included angle of hanging line by simulating nail point with the odontoid posterior horn; The cobb of BOE, the included angle of hanging line by simulating nail point with the odontoid angle bisector optimal length of the simulation nail point to odontoid anterior horn and posterior horn.

Table 3 Axial height and distance from simulation nail points to odontoid tip ( $\mathrm{mm}, \bar{x} \pm \mathrm{s}$ )

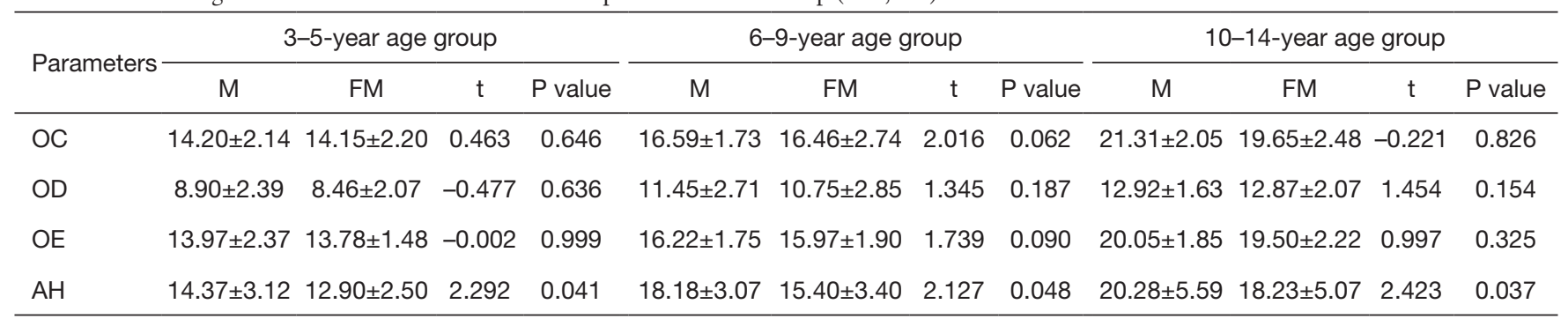

$\mathrm{AH}$, the length of the hanging line of the simulating nail point to the OS odontoideum; OC, the length of the simulating nail point to the odontoid anterior horn; OD, the length of the simulating nail point to the odontoid posterior horn; OE, the odontoid angle bisector length of the simulation nail point to odontoid anterior horn and posterior horn.

and 3.41, 3.89, $4.46 \mathrm{~mm}$ for girls; the cortex bone average transverse diameters were: $5.34,5.50,5.94 \mathrm{~mm}$ for boys, and 5.25, 5.31, $5.62 \mathrm{~mm}$ for girls. These measurements show that the children odontoid cannot hold two screws. So for 3-5-year-old children, we recommend using a $2.5-\mathrm{mm}$ or 3-mm screw diameter; for 6-9 year-old children, a 3-mm or 3.5-mm screw diameter; and for 10-14-year-old children, a $3.5-\mathrm{mm}$ screw diameter. Biomechanical studies have confirmed that there is no significant difference with singleand double-screw fixations in shear stiffness (bending) and torsional stiffness (11-13). The 2 fixation methods provide similar stability in odontoid fractures.

The angle of screw implantation is important. A small angle could easily lead to cortical bone splitting, and it is difficult to achieve fixed effect. A large angle could lead to front fracture separation, which will penetrate the rear of the odontoid and damage the spinal cord. The implant angle should be selected according to the odontoid retroversion angle and the diagonal angle of the odontoid median sagittal plane. We chose the atlantoaxial vertebral 
anterior-inferior edge middle as the nail entry point. The safety angle range should be between the front and rear odontoid tip. Our findings of our study indicate that the simulation nail point to the odontoid anterior horn and posterior horn was not significantly different between the boys and the girls. The screw security range was $16-36^{\circ}$, and the best angle range was $19-22^{\circ}$. This measurement is less than the angle of the normal adult. Therefore, for children, anterior odontoid fracture hollow screw fixations need to be within the safety range.

Hollow lag screw length depends on the axial height, that is, the axial height provides the screw fixed length. We used the diagonal of the odontoid median sagittal plane to simulate the nail channel, that is the odontoid angle bisector optimal length of the simulation nail point to odontoid anterior horn and posterior length angles, and its length could be selected as the reference for screw length. The findings of the present study showed that the axial heights in groups 1-3 were as follows for the boys: 14.37 , $18.18,20.28 \mathrm{~mm}$, respectively, and the average lengths of the simulation screw channel were 13.97, 16.22, and $20.05 \mathrm{~mm}$, respectively. For the girls, the axial lengths were $12.90,15.40$, and $18.32 \mathrm{~mm}$, respectively, and the average lengths of the simulation screw channel were 13.78, 15.97, and $19.50 \mathrm{~mm}$, respectively. Screw length was much longer than the axial trabecular bone height, and the screw must drive into the odontoid cortex bone. This was the only way to ensure that the screw was firmly fixed. Therefore, we recommend a 13-14-mm screw length for 3-5 years, $15-16 \mathrm{~mm}$ for 6-9 years old, and $19-20 \mathrm{~mm}$ for $10-14$ years old.

Conservative therapy is used for children with odontoid fracture; however, when the odontoid fracture is complicated by significant displacement and unstable, surgery is required. Hollow screw fixation is an effective treatment for type II odontoid fractures, and could improve the convergence range of odontoid fractures, prevent atlantoaxial fusion disadvantages, and has good clinical efficacy. Based on our os odontoideum measurement results, it is important to select the appropriate screw diameter, length, and direction according to parameter changes of os odontoideum in children of different ages.

\section{Acknowledgments}

Funding: None.

\section{Footnote}

Reporting Checklist: The authors have completed the MDAR reporting checklist. Available at http://dx.doi.org/10.21037/ tp-20-416

Data Sharing Statement: Available at http://dx.doi. org/10.21037/tp-20-416

Conflicts of Interest: All authors have completed the ICMJE uniform disclosure form (available at http://dx.doi. org/10.21037/tp-20-416). The authors have no conflicts of interest to declare.

Ethical Statement: The authors are accountable for all aspects of the work in ensuring that questions related to the accuracy or integrity of any part of the work are appropriately investigated and resolved. All procedures performed in this study involving human participants were in accordance with the Declaration of Helsinki (as revised in 2013). The study was approved by Ethics Committee of the Second Affiliated Hospital of Wenzhou Medical University (No.: 2021-K-09-01). Individual consent for this retrospective analysis was waived.

Open Access Statement: This is an Open Access article distributed in accordance with the Creative Commons Attribution-NonCommercial-NoDerivs 4.0 International License (CC BY-NC-ND 4.0), which permits the noncommercial replication and distribution of the article with the strict proviso that no changes or edits are made and the original work is properly cited (including links to both the formal publication through the relevant DOI and the license). See: https://creativecommons.org/licenses/by-nc-nd/4.0/.

\section{References}

1. Fassett DR, McCall T, Brockmeyer DL. Odontoid synchondrosis fractures in children. Neurosurg Focus 2006;20:E7.

2. Hosalkar HS, Greenbaum JN, Flynn JM, et al. Fractures of the odontoid in children with an open basilar synchondrosis. J Bone Joint Surg Br 2009;91:789-96.

3. Sherk HH, Nicholson JT, Chung SM. Fractures of the odontoid process in young children. J Bone Joint Surg Am 1978;60:921-4.

4. Maheshwari AV, Jain AK, Dhammi IK. Osteochondroma 
of C7 vertebra presenting as compressive myelopathy in a patient with nonhereditary (nonfamilial/sporadic) multiple exostoses. Arch Orthop Trauma Surg 2006;126:654-9.

5. Sankar WN, Wills BP, Dormans JP, et al. Os odontoideum revisited: the case for a multifactorial etiology. Spine (Phila Pa 1976) 2006;31:979-84.

6. Jones A, Mehta J, Fagan D, et al. Anterior screw fixation for a pediatric odontoid nonunion: a case report. Spine (Phila Pa 1976) 2005;30:E28-30.

7. Platzer P, Thalhammer G, Ostermann R, et al. Anterior screw fixation of odontoid fractures comparing younger and elderly patients. Spine (Phila Pa 1976) 2007;32:1714-20.

8. Haque A, Price AV, Sklar FH, et al. Screw fixation of the upper cervical spine in the pediatric population. Clinical article. J Neurosurg Pediatr 2009;3:529-33.

9. Bailey DK. The normal cervical spine in infants and

Cite this article as: Dou H, Xie C, Wang X, Huang Q. Image measurements of os odontoideum in children. Transl Pediatr 2021;10(2):388-393. doi: 10.21037/tp-20-416 children. Radiology 1952;59:712-9.

10. Jagannathan J, Dumont AS, Prevedello DM, et al. Cervical spine injuries in pediatric athletes: mechanisms and management. Neurosurg Focus 2006;21:E6.

11. Nucci RC, Seigal S, Merola AA, et al. Computed tomographic evaluation of the normal adult odontoid. Implications for internal fixation. Spine (Phila Pa 1976) 1995;20:264-70.

12. Graziano G, Jaggers C, Lee M, et al. A comparative study of fixation techniques for type II fractures of the odontoid process. Spine (Phila Pa 1976) 1993;18:2383-7.

13. Sasso R, Doherty BJ, Crawford MJ, et al. Biomechanics of odontoid fracture fixation. Comparison of the one- and twoscrew technique. Spine (Phila Pa 1976) 1993;18:1950-3.

(English Language Editor: R. Scott) 